\section{Thinking outside the box}

To the Editor: I read your editorial ${ }^{1}$ and whole-heartedly agree with your stance; however, I object to your attack on the knowledge level of family physicians. Over half your article goes on and on about what little FPs can or can't do, in a very cynical manner I might add. I think you forget that FPs provide the bulk of emergency care across our country in rural hospitals, secondary and some tertiary care centres. I disagree with your comment that emergency physicians and FPs are different animals. As a person who practises in both areas I can tell that there is a lot of crossover. FPs are not dummies; most perform very well in emergency situations and have been trained to do so by people like you.

Your commentary started out well, but then you attacked your colleagues instead of continuing to focus on the real problem: bureaucrats who make uninformed decisions.

\section{Alex Brothers, MSc, MD, CCFP(EM) Canmore, Alta.}

\section{Reference}

1. Innes G. Thinking outside the box [editorial]. CJEM 2002;4(5):316.

\section{[The Editor responds:]}

I understand that my editorial might have offended some FPs, and I apologize if it did. My intention was to point out that FPs and EPs are different. Despite Dr. Brothers' opinion, I still believe this is true. We have different training, different practice settings, different case mix, different experience and different procedural skills. We have different comfort zones and we research different problems.

I also recognize that FPs aren't "dummies." Not only do they deliver a large proportion of the emergency care in Canada, they deliver a large proportion of the pediatric, obstetric, geriatric, internal medicine and psychiatric care. Despite this, I have never heard anyone argue that there is no difference between an FP and an obstetrician. Clearly there is crossover between family medicine and EM. There is also crossover between cardiology and ICU, EM and internal medicine, and family medicine and pediatrics. But none are interchangeable. If it is true that FPs and EPs are no different, then the Quebec bureaucrats have come up with a viable solution and I have wasted years of my life.

The flip side of the coin is that EPs are not FPs. The prospect of delivering a baby terrifies me, I don't know how to manage chronic hypertension, diabetes or arthritis, I misdiagnose most rashes, and I don't know how to feed or immunize infants. I am not an FP. Finally, I note that Dr. Brothers has EM training. His knowledge base, skill set and perspective may not be typical of most FPs.

\section{Grant Innes, MD}

Your editorial intrigued me. I don't know all the details of the issue at those Quebec hospitals. I don't know if they had full time ED docs or if they were staffed by GPs. I'm sure there were a few places with too few medical staff, each of them working beyond reasonable limits. I feel for the docs who are working too hard. I feel for the government that wants to maintain service. The problem is complex: In a nutshell it's a case of too few physicians and not enough money. It's too bad they couldn't work something out because it ends up being patients who suffer.

As a rural physician, even with my CCFP(EM), I was insulted by your extremely paternalistic attitude toward so many physicians that are, yes, lowly GPs, working in EDs. Why are you making such an effort to make GPs look like dorks? Don't patronize us with crap from that ivory tower of yours. Your attitude reeks of elitist mumbo jumbo. You are basically telling every doc that is not an FRCP brainchild with a copy of Rosen's shoved up their ass that they are incompetent to work in an ED. I find it very immature to cut down others like you did just to make a point. Your knowledge and work is special and important but don't crap on the rest of us, especially if you want our support.

What you fail to point out is that we are all important and we all have to work together. Probably most of us think the government is doing a poor job right now. Probably most of us think that there need to be some changes to the system. We certainly do have the worst medical system in the world... next to every other system in the world! But if we continue to piss on the next guy with an MD we are doing a big disservice to our profession and our communities. We are all, I hope, just doing the best we can and calling for help when we need it.

Finally, if you feel that you guys are such hotshots then how can you share your vast knowledge with the rest of us peons? Are you going out and giving lectures? Are you taking in physicians for skills upgrading? Are you lobbying the CFPC to teach their residents how to function effectively in EDs? Are you so preoccupied with your intellec- tual drivel that you forget about all the children on the planet that die of dehydration?

ALL of us must work together to make this system work. If we continue to throw up our arms and walk away or wait for more money from the government then we are doomed not because we may miss an unstable $\mathrm{C}$-spine, but because we have forsaken a centuries-old unwritten code of our profession to work together and look after the sick.

\section{Dave Larocque \\ Castlegar, BC \\ PS: I enjoy reading the Journal.}

\section{[The Editor responds:]}

I believe that the worst person to staff an ED is someone who has to be legislated there, and that the best person is an EP. To make this point, I listed some key knowledge and skills that I did not possess after completing my family medicine residency, and that I acquired during EM training. My intention was not to suggest that FPs are "dorks;" it was to point out that EPs have a deeper knowledge of EM than non-EPs. And all of the skills listed - from recognizing methanol poisoning to managing difficult airways — are important EM skills. They are not intellectual drivel or elitist mumbo jumbo.

Dr. Larocque suggests incorrectly that my definition of EM competence involves Royal College certification. In fact, my editorial suggests nothing of the sort. Rather than being "anti-CCFP(EM)," I have chosen to work at a $\mathrm{CCFP}(\mathrm{EM})$ residency site, where, among other things, I helped establish research fellowships aimed primarily at $\mathrm{CCFP}(\mathrm{EM})$ physicians who would otherwise have less opportunity for academic careers. As CJEM Editor, I instituted a policy of not publishing the FRCP or CCFP(EM) designation after authors' names because I believe it is counterproductive to highlight differences between EPs.

The answers to Dr. Larocque's other questions are Yes, Yes and Yes. In the last 5 years I have given 6 to 7 lectures per year to parttime EPs in places like Dawson Creek, Yellowknife and Campbell River. Our ED offers 1- to 6-month skills enhancement programs for rural physicians. We are actively lobbying the CFPC for more CCFP(EM) residency positions, and we are trying to develop EM residencies that include substantial training time in rural settings. I agree with Dr. Larocque that we must all work together, and it's none of my business where those damn FRCPs put Rosen's textbook when they're not reading it.

Grant Innes, MD 